\title{
Pertukaran Pelajar Unram-UPM : Inovasi Pembelajaran Mbkm Dalam Menumbuhkan Ketangguhan Lulusan Sarjana Kehutanan
}

\author{
Sitti Latifah ${ }^{1}$, Zharfan Gibran ${ }^{1}$, Hayatus Saadiah ${ }^{1}$, Gian Prasetyawijaya ${ }^{1}$, Andy Soraya \\ N.C1, Akbar Al Imam¹, B. Aliyasita Dwi Mustika', Nurul Lasmini' ${ }^{1}$, Zamhur Ahmad ${ }^{1}$ \\ ${ }^{1}$ Prodi Kehutanan, Fakultas Pertanian, Universitas Mataram, Indonesia
}

Alamat korespondensi : sittilatifah@unram.ac.id

\begin{abstract}
ABSTRAK
Perubahan yang cepat dalam dunia Pendidikan tinggi menuntut Perguruan tinggi untuk dapat merubah cara bepikir (mindset), sikap dan dan tingkah (attitude and behaviour) dan cara baru dalam mengerjakan sesuatu (way of doing things) civitas akademikanya, sehingga dapat menghasilkan lulusan yang adaptif dan tangguh menghadapi perubahan dan ketidakpastian. Hasil tracer study Prodi Kehutanan dari 2013 hingga 2020 menunjukkan kecenderungan kemampuan komunikasi, berbahasa asing dan kemampuan teknologi belum meningkat. Salah satu solusi yang ditawarkan adalah melalui kegiatan pertukaran pelajar antara Prodi Kehutanan Univerd dengan Fakulti Perhutanan UPM sebagai mitra. Pertukaran pelajar merupakan satu bentuk pembelajaran yang sejalan dengan Kebijakan Pemerintah terkait Standar Nasional Pendidikan Tinggi dan Kebijakan Merdeka Belajar - Kampu Merdeka (MBKM). Tujuan dari kegiatan pertukaran pelajar ini adalah untuk memberikan pengalaman belajar di luar institusi dengan menjunjung tinggi kesetaraan dalam pembelajaran. Metode pembelajaran yang digunakan sangat beragam, mulai dari diskusi kelompok, simulasi, pembelajaran kooperatif hingga pembelajaran berbasis masalah. Bentuk-bentuk pertukaran pelajar yang telah dilaksanakan dalam kurun waktu 2015-2019 adalah pertukaran pelajar yang diperkaya dengan seminar, pengabdian kepada masyarakat, praktik lapang, kuliah dan seminar dalam bentuk Kem Perhutanan dan Student Mobility. Hasil menunjukkan bahwa mahasiswa Universitas Mataram dapat bersaing dan berhasil meraih nilai tertinggi dalam setiap kegiatan Kem Perhutanan.
\end{abstract}

Keywords : UPM, Unram, Pertukaran Pelajar, Student Mobility, Kem Perhutanan.

\section{PENDAHULUAN}

Perubahan yang cepat dalam dunia Pendidikan tinggi menuntut Perguruan tinggi untuk dapat merubah cara bepikir (mindset), sikap dan dan tingkah (attitude and behaviour) dan cara baru dalam mengerjakan sesuatu (way of doing things) civitas akademikanya, sehingga dapat menghasilkan lulusan yang adaptif dan tangguh menghadapi perubahan dan ketidakpastian. Maka daripada itu kebijakan kurikulum harus mengelaborasi kemampuan peserta didik pada dimensi pedagogik, kecakapan hidup, kemampuan hidup bersama (kolaborasi), berpikir kritis, dan kreatif. Peserta didik harus mempunyai soft skills, transversal skills, keterampilan hidup, dan keterampilan yang secara kasat tidak terkait dengan bidang pekerjaan dan akademis tertentu saja. Kurikulum harus memperhatikan perkembangan pendidikan berbasis vokasional dengan ragam keterampilan yang tidak sekadar mengedepankan konsep link and match antara perguruan tinggi dengan dunia industri, tetapi juga menekankan kapasitas lulusan yang lincah, adaptif, dan sensitif terhadap perubahan lingkungan industri dan ekonomi. 
Implementasi kurikulum di perguruan tinggi mengalami degradasi yang keluar konteks dan tidak lagi berorientasi pada pencapaian kemampuan peserta didik pada pemahaman ilmu dalam konteks praktik hidup dan keseharian (kompetensi keterampilan hidup), namun hanya berkisar pada target pencapaian kompetensi peserta didik yang digambarkan pada nilai-nilai akademik saja. Untuk bisa beradaptasi dengan perubahan yang diakibatkan oleh revolusi industri 4.0, seseorang harus memiliki kemampuan yang tidak akan bisa dilakukan oleh mesin, seperti kemampuan untuk memecahkan masalah atau kreativitas.

Perguruan tinggi harus menerapkan pendidikan yang berimbang antara hard skills dan soft skills agar menghasilkan lulusan yang kompeten di bidangnya. Mahasiswa dilibatkan dalam proses belajar dan kehidupan kampus secara terstruktur dan terintegrasi. Mahasiswa dilatih untuk bisa bersikap kritis melalui sistem pembelajaran yang juga menekankan pengembangan soft skills, selain keterampilan teknis, lulusan perguruan tinggi akan bisa lebih mampu beradaptasi secara cepat terhadap perubahan serta memiliki bekal yang mumpuni untuk menghadapi masa depan dan pengembangan kariernya dalam menghadapi perkembangan yang terjadi pada era revolusi industri 4.0 dan masyarakat 5.0.

Hasil tracer study Prodi Kehutanan dari 2013 hingga 2020 menunjukkan kecenderungan kemampuan komunikasi, berbahasa asing dan kemampuan teknologi belum meningkat (Tajidan, et.al., 2020). Salah satu solusi yang ditawarkan adalah melalui kegiatan pertukaran pelajar antara Prodi Kehutanan Unram dengan Fakulti Perhutanan UPM sebagai mitra. Pertukaran pelajar merupakan satu bentuk pembelajaran yang sejalan dengan Kebijakan Pemerintah terkait Standar Nasional Pendidikan Tinggi dan Kebijakan Merdeka Belajar Kampu Merdeka (MBKM). Kedua kebijakan ini meiliki konsep memberikan pengalaman belajar bagi mahasiswa baik di prodi lain dalam satu institusi atau lain institusi serta lembagalembaga yang dapat meningkatkan kemampuan lulusan, seperti: lembaga pemerinta, perusahaan (swasta, BUMN, BUMD), Yayasan, LSM dan perkumpulan lainnya yang berbadan hukum. Selain itu kegiatan pertukaran pelajar ini merupakan upaya mewujudkan proses pembelajaran yang inovatif dan menyiapkan kompetensi mahasiswa agar lebih link and match dalam menghadapi perubahan sosial, budaya, masa depan yang cepat berubah dan kemajuan teknologi yang pesat sesuai dengan tuntutan zaman dalam menghadapi ekosistem VUCA (Volatility, Uncertainity, Complexity, Ambiguity) dan tentunya lebih kompetitif jika VUCA kita artikan dengan Vision, Understanding, Clarity, dan Agility (Fadillah et al. 2019).

Tujuan dari kegiatan pertukaran pelajar ini adalah untuk memberikan pengalaman belajar di luar institusi dengan menjunjung tinggi kesetaraan dalam pembelajaran.

\section{METODE KEGIATAN}

Metode yang digunakan dalam kegiatan pertukaran pelajar ini mengusung konsep fasilitasi yang berorientasi pada metode pembelajaran partisipatif dan pendidikan orang dewasa (POD), dengan bentuk-bentuk sosialisasi, pendampingan dan pembelajaran yang digunakan sangat beragam, mulai dari diskusi kelompok, simulasi, pembelajaran kooperatif hingga 
pembelajaran berbasis masalah. Metode evaluasi menggunakan standar yang diterapkan di UPM.

Sementara tahapan kegiatan yang dilakukan adalah sebagai berikut : (1). Persiapan; meliputi kegiatan komunikasi antara kedua belah pihak, persiapan administrasi dan penjaringan calon mahasiswa yang akan menjadi peserta (2) Penyiapan dan Penyusunan materi pendampingan, yaitu; (a) materi tentang persiapan keikutsertaan, tata tertib, administrasi, pendaftaran dan (b) materi tentang modul-modul yang biasa dipergunakan untuk kegiatan pertukaran pelajar. (3) Pelaksanaan kegiatan yang meliputi (4) Evaluasi; berupa capaian hasil proses pembelajaran dan diberikan dalam bentuk nilai (GPA).

\section{HASIL DAN PEMBAHASAN}

Kerjasama antara Prodi Kehutanan Unram dan Fakulti Perhutanan UPM yang dimulai pada tahun 2015 merupakan pengembangan dari MOU antara Unram dan UPM dan dapat dikatakan sebagai cikal bakal implementasi kebijakan standar nasional dikti dan kebijakan MBKM. Adapun proses pengembangan pertukaran pelajar melalui beberapa tahapan, yaitu : (1). Pengembangan MOU antara Unram dan UPM, (2). Pengembangan kuliah umum dan seminar internasional di Unram, (3). Pengembangan kuliah lapang bersama di Unram dan (4) Pengembangan kuliah lapang di UPM.

Beberapa bentuk kegiatan yang dibangun semejak 2015 terdiri dari : (1). Kuliah umum oleh para dosen dan seminar internasional, baik di UPM maupun di Unram (2015-2016), (2) Student Mobility, dimana 54 mahasiswa pada tahun 2015 dan 23 orang mahasiswa UPM pada tahun 2017 mengadakan kuliah lapang bersama mahasiswa Unram (kurang lebih 90 orang) dengan tema perkuliahan terkait dengan pengelolaan kawasan hutan, ekowisata dan perhutanan sosial, (3). Kem Perhutanan, merupakan kegiatan perkemahan yang melibatkan mahasiswa UPM dan beberapa universitas dari Indonesia, sepert Unram, IPB, UB, Unhas dan USU. Mahasiswa Universitas Mataram telah mengikuti kegiatan Kem Perhutanan pada tahun 2018 dan 2019 dengan mengirimkan masing-masing 4 (empat) orang mahasiswa. Proses pembelajaran masing-masing program melibatkan berbagai jawatan kehutanan dan masyarakat pengelola hutan sebagai stakeholder. Salah satu kegiatan pertukaran pelajar yang memberikan pengalaman positif bagi berkembangnya kemampuan mahasiswa adalah Kem Perhutanan.

Tahapan penyelenggaraan kegiatan Kem Perkemahan sebagai berikut :

1). Persiapan; meliputi kegiatan komunikasi antara kedua belah pihak, persiapan administrasi dan penjaringan calon mahasiswa yang akan menjadi peserta. Peserta mendaftar dengan menyertakan beberapa persyaratan seperti : CV, letter of motivation, formulir dan credit transfer, serta surat komitmen untuk pembiayaan. Setelah mendaftar, kemudian calon peserta harus melalui test wawancara. 


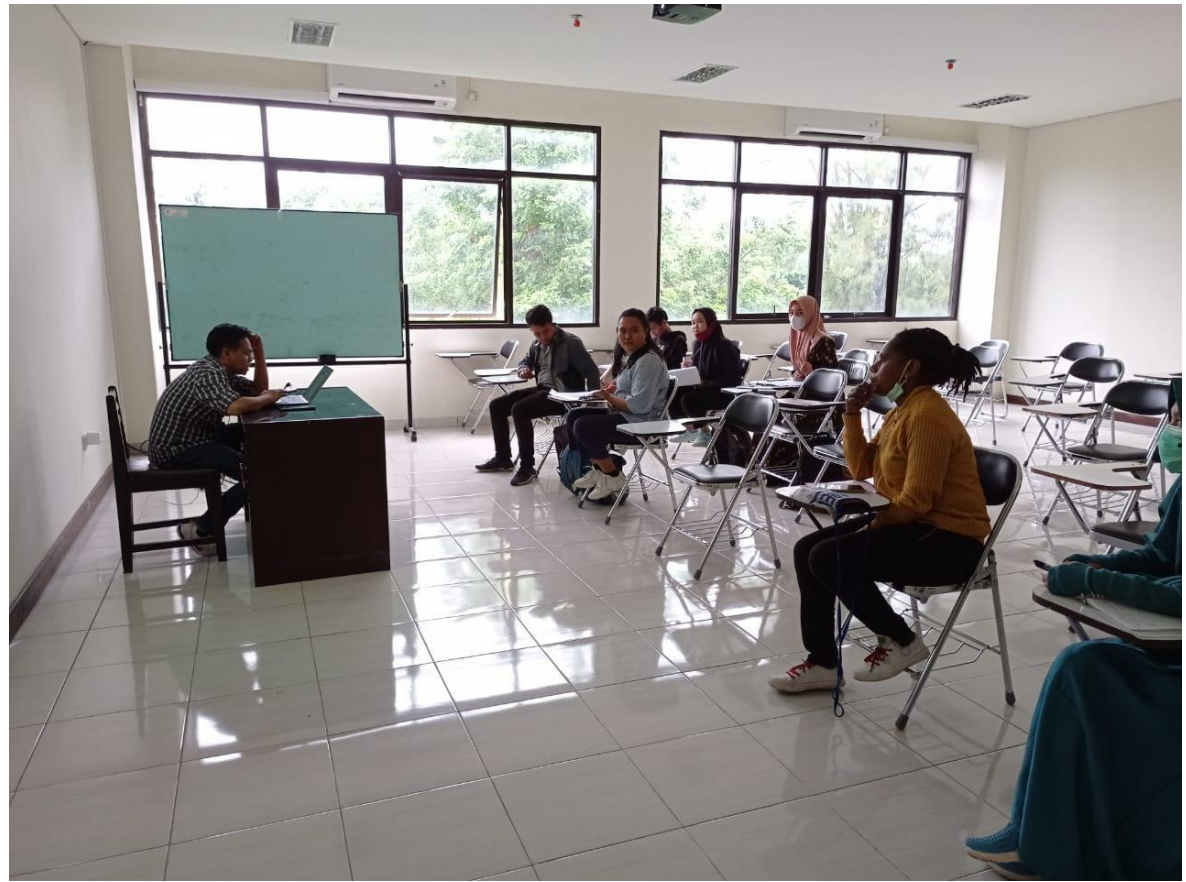

Gambar 1. Pendaftaran dan Wawancara

(2) Penyiapan dan Penyusunan materi pendampingan merupakan kegiatan menyiapkan bahan-bahan dan materi yang akan disampaikan pada saat pendampingan terhadap calon peserta dengan tujuan menyiapkan mental. memotivasi dan pengetahuan agar mahasiswa dapat menyesuaikan diri secara cepat terhadap kondisi di UPM. Adapun materi yang disampaikan adalah : (a) materi tentang persiapan keikutsertaan, tata tertib, administrasi, pendaftaran dan motivasi serta (b) materi tentang modul-modul yang biasa dipergunakan untuk kegiatan pertukaran pelajar, khususnya Kem Perhutanan.

\section{(3) Pelaksanaan kegiatan}

Peserta yang mengikuti kegiatan KEM Perhutanan pada tahun 2018 berjumlah 145 orang terdiri dari 129 orang mahasiswa semester 2 jurusan kehutanan UPM dan 16 orang delegasi dari 4 kampus Indonesia (IPB, UB, Unhas dan Unram) dan pada tahun 2019, total berjumlah 154 orang terdiri dari 134 orang mahasiswa semester 2 jurusan kehutanan UPM dan 20 orang delegasi dari 5 universitas di Indonesia (IPB, UB, Unhas, Unram dan USU).

Metode pembelajaran yang digunakan dalam proses Forestry Camp (FC) selama kurun waktu 14 hari menggunakan metode studi lapangan. Selama 14 hari, seluruh peserta ditempatkan di Hutan Pendidikan yang dikelola oleh UPM, yaitu Hutan Simpan Ayer Hitam (HSAH) yang terletak di Sultan Idris Shah Forest Education Center (SISFEC), Puchong, Malaysia.

Dalam proses pembelajarannya digunakan 2 (dua) modul Forestry Camp (FC) yaitu (1) Modul FC 1: Kemandirian Hutan, yang terdiri dari sub modul Forest Survival, Membangun 
HSAH Sebagai Pusat Rekreasi dan Ekoplancongan, Hutan Untuk Masa Hadapan dan Biosumber Hutan; (2) Modul FC 2: Cabaran Kembara Berkumpulan.

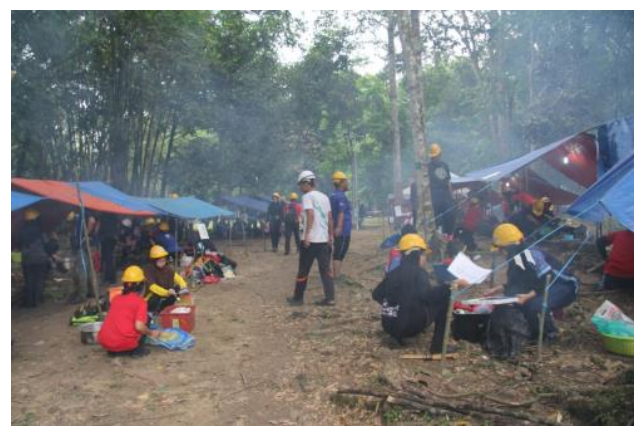

Gambar 2. Kegiatan Forest Survival

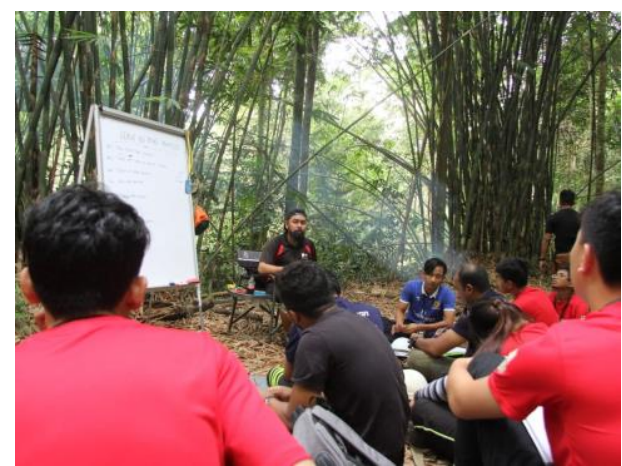

Gambar 4. Kegiatan Pengenalan Hutan Untuk Masa Hadapan

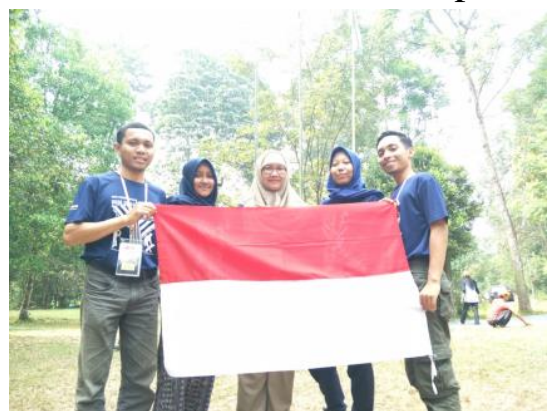

Gambar 6. Kunjungan Dari Dosen Pendamping

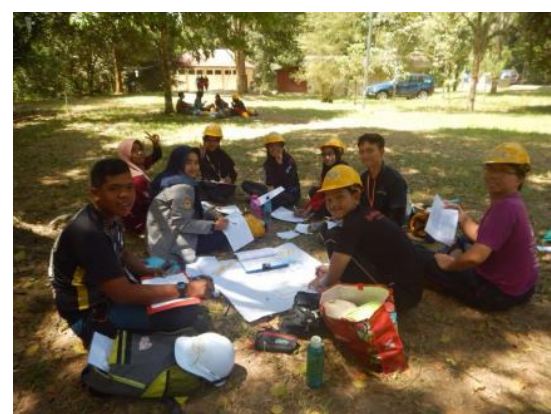

Gambar 3. Kegiatan Perancangan Design Tapak HSAH

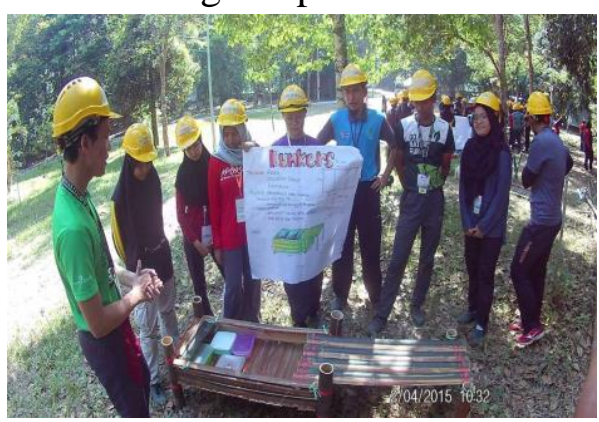

Gambar 5. Kegiatan Pemanfaatan Biosumber Hutan

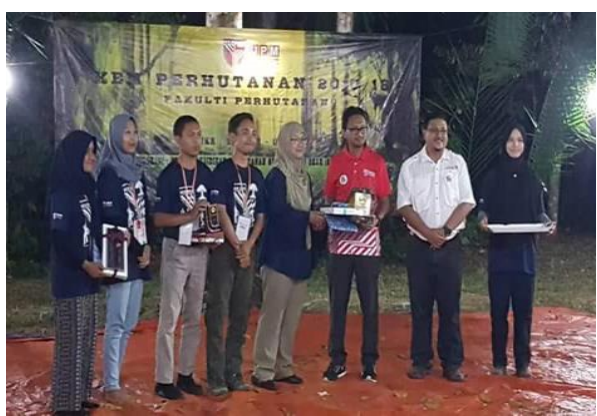

Gambar 7. Closing Ceremony

(4) Evaluasi merupakan capaian hasil proses pembelajaran dan diberikan selama proses Kem Perkmahan dalam bentuk nilai (GPA).

Proses penilaian dari setiap peserta dilakukan oleh setiap pemateri pada setiap modulnya. Penilaian didasarkan pada: pengetahuan, kemahiran teknikal, kemahiran sosial dan bertanggungjawab, kemahiran berkomunikasi, professionalism, nilai, sikap dan etika, kemahiran kepemimpinan. Salah satu bentuk dari aspek yang dinilai adalah seperti kuis di 
setiap akhir pembelajaran modul dan sub modulnya, presentasi baik secara individu maupun kelompok serta praktik lapangan yang berkaitan dengan materi yang diberikan.

Hasil dari capaian proses pembelajaran diberikan dalam bentuk nilai (GPA) yang dimana delegasi dari Universitas Mataram memperoleh hasil A- (3 orang) dan A (1 orang) pada tahun 2018 dan hasil A (4 orang) pada tahun 2019.

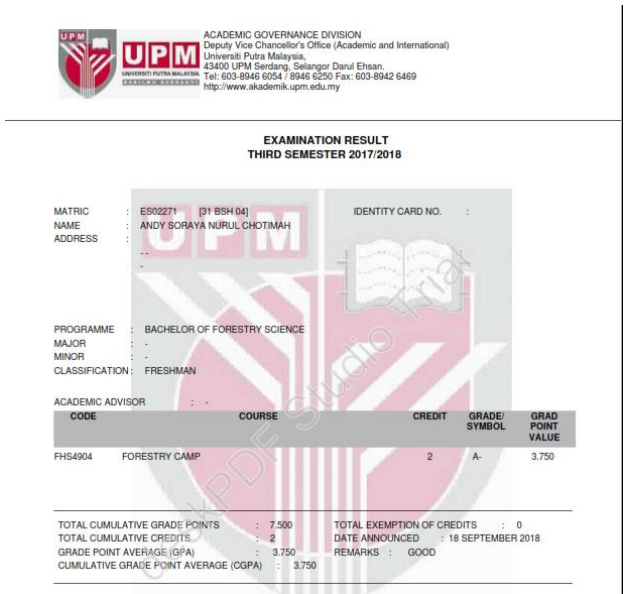

Gambar 8. GPA Peserta Tahun 2018

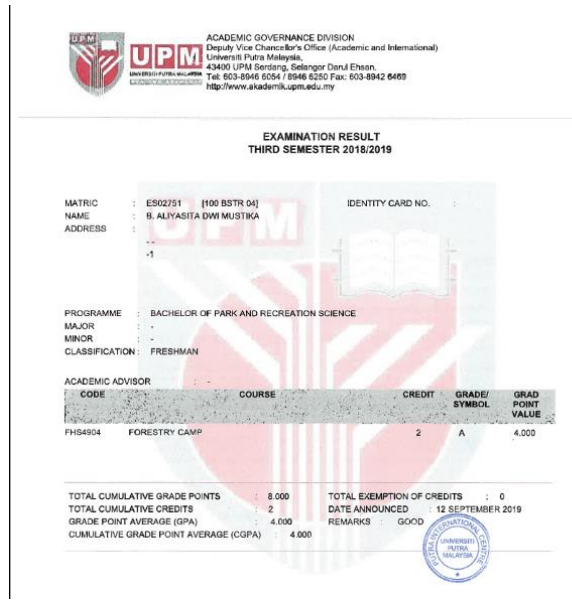

Gambar 9. GPA Peserta Tahun 2019

\section{KESIMPULAN DAN SARAN}

Hasil menunjukkan bahwa kegiatan Kem Perhutanan memberikan manfaat dan pengalaman serta meningkatkan percaya diri untuk berkompetisi dengan mahasiswamahasiswa kehutanan secara global. Hal tersebut diperlihatkan dengan capaian mahasiswa Universitas Mataram yang berhasil meraih nilai tertinggi dalam setiap kegiatan Kem Perhutanan. Akan tetapi permasalahan yang didapat adalah proses transfer nilai ke Unram belum dapat dilaksanakan. Tantangan kedepan adalah bagaimana menawarkan pula mata-mata kuliah di Prodi Kehutanan seperti Forestry Camping dan Praktek Kerja Lapang kepada mahasiswa UPM, serta pengembangan bentuk magang yang ditawarkan oleh pihak UPM kepada Unram.

\section{UCAPAN TERIMA KASIH}

Penulis mengucapkan terima kasih kepada Universitas Mataram yang telah memberi dukungan financial terhadap pengabdian ini.

\section{DAFTAR PUSTAKA}

Fadillah, Achmad dkk. 2019. IPB 4.0 Pemikiran, Gagasan dan Implementasi. Bogor: Penerbit IPB Press.

Tajidan, dkk. 2020. Studi Pelacakan (Tracer Study) Alumni dan Pengguna Lulusan Fakultas Pertanian Universitas Mataram. Laporan Penelitian : tidak dipublikasikan. 